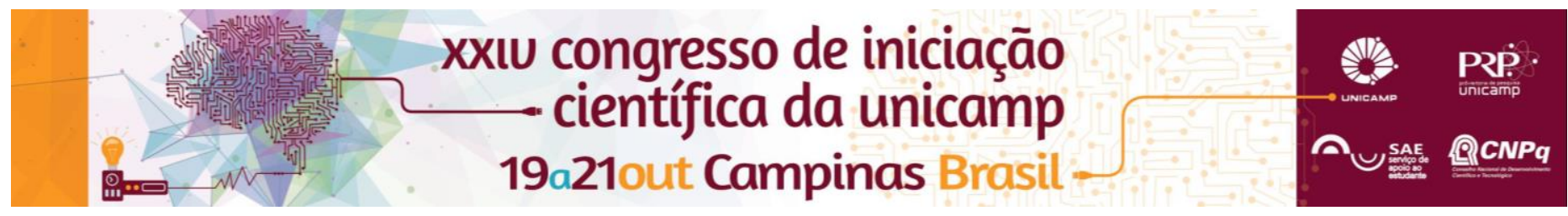

\title{
Análise de chumbo em matrizes como concreto, madeiras, tijolos e revestimentos de parede.
}

\author{
Aline Raquel Fávero*, Profa. Dra. Adriana, V. Rossi (Orientadora)
}

\begin{abstract}
Resumo
Componentes comuns de projéteis de armas de fogo são antimônio, bário e chumbo, sendo que seus íons acabam aparecendo como resíduos de disparos dessas armas. Amostras como concretos, tijolos e madeiras são de interesse da Química Forense para confirmação desses disparos em cenas de crime. Métodos utilizando reações em spot-test permitem o emprego de pequenos volumes de reagente e amostra além indicar visualmente o produto desejado por meio da variação da cor ou aparecimento de precipitado e neste trabalho foram usadas para detectar resíduos de chumbo provenientes de disparo de armas de fogo. Foi utilizada a reação de rodizonato de sódio com íons chumbo que gera um produto avermelhado cuja observação pode servir para comprovar um disparo de projétil contendo chumbo. Após estudos de otimização da reação com rodizonato, desenvolvemos uma proposta para detectar chumbo em amostras de concreto e madeira para identificar resíduos de disparos de projéteis de armas de fogo .
\end{abstract}

Palavras-chave: Chumbo, Rodizonato de Sódio, Concreto.

\section{Introdução}

O desenvolvimento de um método para a detecção de chumbo em matrizes tais como concreto, madeiras, entre outras, é de interesse para o campo da Química Forense. O projétil de armas de fogo é composto, em geral, por ligas de chumbo com elementos como bário e antimônio, sendo que seus íons podem aparecer como resíduos dos disparos dessas armas.

Para a identificação do chumbo nas matrizes e, por consequência, a comprovação de um disparo utilizou-se como reagente o rodizonato de sódio (ROD) que em presença de $\mathrm{Pb}(\mathrm{II})$ produz um complexo (PbROD) colorido. Em meio neutro ocorre a precipitação de um composto violeta e, em meio ácido, vermelho. ${ }^{1} \mathrm{O}$ trabalho de Castro indica as condições experimentais otimizadas, sendo que em $\mathrm{pH} 2,78$ outros ânions presentes não interferem na reação.

Reações que envolvem pequenos volumes de reagente e amostra são chamadas de spot test. Um suporte muito adequado para spot tests é o papel que têm como vantagens: baixo custo, afinidade com produtos químicos além do fato do líquido ficar confinado pelos canais microfluídicos do papel. ${ }^{3}$

\section{Resultados e Discussão}

Procedeu-se à utilização de solução de ROD 9,96 $\mathrm{mmol} / \mathrm{L}$ em solução tampão de tartarato de sódio 0,2 $\mathrm{mol} / \mathrm{L}$ em $\mathrm{pH} 2,78$. Foram realizados diversos testes em relação à manipulação da amostra e à adição do reagente. Ficou estabelecido que a raspagem do papel cortado em dimensões 2,5 x 2,0 cm (já impregnado com $10 \mu \mathrm{L}$ de ROD) diretamente na amostra era adequada para visualizar a mudança de coloração. Outro parâmetro estudado foi a estabilidade do ROD no papel após sua aplicação, tendo sido notado que o uso do papel imediatamente após aplicação de ROD e secagem à temperatura ambiente levava à maior intensidade da cor avermelhada, o que foi considerado mais adequado para visualização do resultado do teste.

Foram utilizadas amostras de concreto e madeira com resíduos de disparos de armas de fogo cedidas pelo Instituto Nacional de Perícia Criminal e pela Escola Preparatória de Cadetes do Exército - EsPCEx.

As raspagens foram feitas diretamente em área atingida por disparo e, também foram realizadas raspagens em DOI: 10.19146/pibic-2016-50705 locais distantes, para serem consideradas como "branco" de comparação. A Figura 1 indica as cores do produto da reação do papel com ROD com a amostra de concreto.

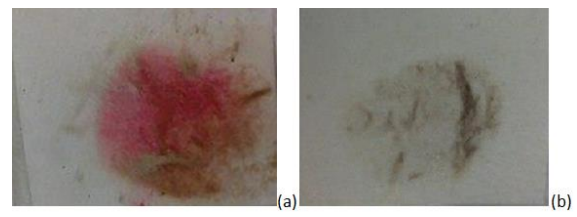

Figura 1. Produto da reação com ROD pela raspagem da amostra de concreto em região com (a) e sem (b) disparo.

Pela raspagem direta do papel na amostra, notou-se a coloração avermelhada até regiões a uma distância média de $6 \mathrm{~cm}$ ao redor do disparo, admitindo variações em função do calibre da arma usada. Isso evidencia que há fragmentação e espalhamento de resíduos do projétil, o que deve ser considerado para avaliação de resultados quando se busca associar o teste positivo com a efetiva realização de disparo por arma de fogo.

\section{Conclusões}

A detecção de chumbo em concreto a partir da sua reação com ROD é eficiente e, portanto, importante para identificar disparos de armas de fogo. É necessário ressaltar que o resultado positivo pode ser observado numa área com raio $6 \mathrm{~cm}$ ao redor do centro atingido devido à dispersão dos resíduos do projétil. Como existem projéteis encapsulados que não contêm chumbo, cujos resíduos também podem ser passíveis de detecção a partir do reagente $\mathrm{ROD}$, é preciso ajustar o $\mathrm{pH}$ da solução de ROD viabilizar a detecção de outros íons para detectar a realização do disparo.

\section{Agradecimentos}

À UNICAMP pela bolsa PIBIC-SAE.

A Márcio Talharini (Perito Criminal Federal do Instituto Nacional de Criminalística) e aos docentes e instrutores da EsPCEx que forneceram as amostras com resíduos de disparos de armas de fogo.

\footnotetext{
${ }^{1}$ Feigl, F.; Anger, V. Spot tests in Inorganic Analisys, $6{ }^{\text {th }}$ ed. Amsterdam: Elsevier, 1972.

${ }^{2}$ Castro, P. P. Spot test para chumbo em solos. 125f. Tese (Doutorado). Instituto de Química. Universidade Estadual de Campinas. 2013.
}

${ }^{3}$ Li, X.; Ballerini, D. R.; Shen, W. Biomicrofluids, 6, 1-13, 2012. 